\title{
Vulvar Angiokeratoma
}

National Cancer Institute

\section{Source}

National Cancer Institute. Vulvar Angiokeratoma. NCI Thesaurus. Code C8596.

An uncommon benign lesion in the vulva. It manifests with multiple papular lesions which are purple in color. They are usually asymptomatic. Histologically, there is hyperkeratosis, papillomatosis, and dilated blood vessels in the papillary dermis. 